\title{
Neutron Reflectometry Investigations of Interfacial Structures of Ti/TiN Layers Deposited by Magnetron Sputtering
}

E. B. Watkins ${ }^{1}$, J. Majewski ${ }^{2,}{ }^{*}$, J. K. Baldwin' ${ }^{2}$, Y. Chen ${ }^{2}$, N. $\mathrm{Li}^{2}$, R. G. Hoagland ${ }^{4}$, S.K.

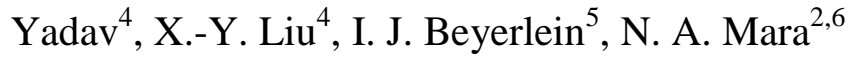

${ }^{1}$ MPA-11, Materials Physics and Application Division, Los Alamos National Laboratory, Los Alamos, New Mexico 87545, USA

${ }^{2}$ Center for Integrated Nanotechnologies, Materials Physics and Application Division, Los Alamos National Laboratory, Los Alamos, New Mexico 87545, USA

${ }^{3}$ Department of Chemical Engineering, University of California, Davis, CA, 95616.

${ }^{4}$ MST-8, Materials Science and Technology Division, Los Alamos National Laboratory, Los Alamos, New Mexico 87545, USA

${ }^{5}$ T-3, Theoretical Division, Fluid Dynamics and Solid Mechanics, Los Alamos National Laboratory, Los Alamos, New Mexico 87545, USA

${ }^{6}$ Institute for Materials Science, Los Alamos National Laboratory, Los Alamos, New Mexico 87545, USA

*Corresponding author: jarek@lanl.gov

\begin{abstract}
:
Nanolayered metal-ceramic composite systems provide the possibility to produce new materials with exceptional strength, toughness, and radiation resistance not exhibited by their individual constituents. The unusual behaviors are frequently attributed to the high density of internal interfaces. Most layered structures studied to date contain sharp interfaces and the synthesis of more diffuse interfacial structures, where the interface is
\end{abstract}


graded out of the interface plane, has not been deeply explored. Here we show how neutron reflectometry was used to study the structure of magnetron sputter deposited titanium and titanium nitride (Ti/TiN) layers as a function of deposition parameters: temperature, rate of $\mathrm{N}_{2}$ flow or pressure, electrical bias applied to the sample, and orientation of the ion source relative to the sample. These different deposition and postprocessing strategies resulted in profound changes in the structure of the interfacial region between the two components in $\mathrm{Ti} / \mathrm{TiN}_{\mathrm{x}}$ bilayers. The results show that temperature and low step-wise $\mathrm{N}_{2}$ flow rates, but not electrical bias, can form graded interfaces in a controlled manner.

Keywords: titanium; titanium nitride; engineered interfaces; composite materials; neutron reflectivity

\section{INTRODUCTION}

It has long been realized that interfaces play a critical role in the structural properties of nanolayered composites [1-4]. Over the years, the aim in engineering interfaces has been to radically improve several structural properties simultaneously, such as strength, ductility, and fracture toughness [5,6]. In this pursuit, intense research has been dedicated toward better understanding of how interfaces govern the interactions and reactions of discrete defects generated during deformation. For dissimilar metal-metal interfaces, it has been shown that the structure of the interface, including its atomic structure, misfit dislocation network, and crystallographic character, can greatly affect many properties, 
such as dislocation annihilation and nucleation, twinnability, recovery from radiation induced defects, thermal stability, and strength [7-11].

Compared to bimetal interfaces, engineering metal-ceramic interfaces in nano-layered composites have received far less attention and yet they represent a promising and relevant frontier for advanced nanomaterials design. As a representative example, here we focus on the Ti/TiN system. With an unprecedented combination of high hardness, chemical resistance to corrosion, bio-compatibility, diffusion barrier properties, and high electrical conductivity, titanium nitride (TiN) has been widely used in many industrial applications [12-16]. It has been found, for instance, that when TiN is coupled to a layer of metal to form a nano-laminate composite, correlated fracture toughness can be significantly enhanced [17,18]. Further, enhanced wear resistance $[19,20]$, fracture toughness [21], corrosion protection [22,23], and improved performance as a diffusion barrier $[24,25]$ have been frequently reported in Ti/TiN nano-layered composites. For similar metal-ceramic systems, prior in situ nano-indentation experiments have demonstrated the exciting possibility of inducing plasticity in the ceramic but only when the interface spacing is extremely fine $(<5 \mathrm{~nm})$ [26-30]. Thicker layers, however, produce the typical brittle response expected of a ceramic composite.

The interfaces studied in the aforementioned metal-metal and metal-ceramic nanocomposites can be classified as sharp interfaces. In the case of metal-ceramic nanoscale composites, current questions are whether another layer size distribution or graded interface structure can enhance crack suppression in the ceramic for layers thicker 
than $5 \mathrm{~nm}$. A few recent efforts have shown that the hardness of compositionally modulated $\mathrm{Ti} / \mathrm{TiN}$ multilayered films exhibit monotonically increasing hardness with decreasing layer thickness, even for bilayer thickness as small as $2.5 \mathrm{~nm}[31,32]$. However in other reports, the peak hardness for bilayer period thickness ranging from 10 to $140 \mathrm{~nm}$ [33-36] decreases with smaller period thicknesses. While these few works are conflicting, they nonetheless hint at the great potential that interfaces can play in influencing the mechanical properties of metal-ceramic composite properties. It is also clear that more work could be dedicated to alternative interface design, in particular deviating from the sharp interface paradigm and moving towards more diffuse or graded interfaces.

Many of the nano-layer composites studied to date have been fabricated through physical vapor deposition (PVD). When made in this way, it is common to find limited chemical intermixing between the two dissimilar materials [37-41]. However, there are many PVD processing parameters that have yet to be explored that could provide means to fine-tune the extent of the interface mixing and out-of-plane broadening of the bi-phase interface during the deposition process. In this work, we explore the influence of multiple reactive magnetron sputtering deposition parameters on chemical stoichiometry and interface morphology of $\mathrm{Ti} / \mathrm{TiN}$ bilayers. We aim to obtain broadened or "three-dimensionally graded" Ti/TiN interface structures in a number of ways: temperature, rate of $\mathrm{N}_{2}$ flow or pressure, electrical bias applied to the sample and orientation of the ion source relative to the sample. Neutron reflectivity (NR) has been applied to analyze the structure of the $\mathrm{Ti} / \mathrm{TiN}$ bilayers. Neutron scattering provides high contrast between $\mathrm{Ti}$ and $\mathrm{TiN}_{\mathrm{x}}$, high 
sensitivity to the nitrogen content, and $\AA$-level spatial resolution to characterize thickness of layers and extent of interfacial roughness. We find that deposition temperature and low step-wise $\mathrm{N}_{2}$ flow rates can form graded interfaces in a controlled manner.

\section{EXPERIMENTAL DETAILS AND DATA ANALYSIS}

\subsection{Deposition of Ti/TiN bilayers}

The samples studied here were bilayers of a metal, titanium (Ti), and ceramic, titanium nitride $\left(\mathrm{TiN}_{\mathrm{x}}\right.$, where $x \neq 1$ represents off-stoichiometric compositions). Each $\mathrm{Ti} / \mathrm{TiN}_{\mathrm{x}}$ sample was deposited as a bilayer on a silicon ( $\mathrm{Si}$ ) substrate using magnetron sputtering. All the samples were deposited on (100) silicon substrates starting with $99.99 \%$ pure Ti. The Ti layer was sputtered at a pressure of 3 mTorr, an Ar flow rate of 30 square cubic centimeters per minute $(\mathrm{sccm})$, and $300 \mathrm{~W}$ DC power applied to the 2 inch sputtering target. The majority of the samples, listed in Table $1,(A-F, H-I)$ were synthesized by reactive sputtering techniques with 2 notable exceptions $(J, K)$ as described in Table 1. The critical parameters that were changed during the deposition process were (i) $\mathrm{N}_{2}$ gas flow, (ii) temperature (iii) substrate bias conditions, and (iv) orientation of the ion source relative to the sample. For all samples the substrate bias, $\mathrm{N}_{2}$ flow rates, or temperature were varied as indicated in Table 1 . For example, sample $C$ was deposited with the substrate at $700^{\circ} \mathrm{C}$ and remained at that temperature throughout the deposition with a stepwise increase in $\mathrm{N}_{2}$ flow $(0,1,2,3 \mathrm{sccm})$ and no applied bias. For sample $G$, the 
initial $100 \AA \mathrm{Ti}$ layer and the first of three $\mathrm{TiN}_{\mathrm{x}}$ layers were deposited at room temperature (RT) with the second and third $\mathrm{TiN}_{\mathrm{x}}$ layers deposited at $350^{\circ} \mathrm{C}$ and $700^{\circ} \mathrm{C}$, respectively using a constant $\mathrm{N}_{2}$ flow $(3 \mathrm{sccm})$ and no applied bias. In the case of samples $J$ and $K, 200 \AA$ thick Ti layers were deposited and the samples were held in a 10 mTorr nitrogen atmosphere with either a RF bias applied to the substrate $(J)$ or with the substrate temperature increased to $700^{\circ} \mathrm{C}$ and maintained for $900 \mathrm{sec}(K)$. The ramp of temperature from ambient to $700^{\circ} \mathrm{C}$ required $420 \mathrm{sec}$. During that time the flow of $\mathrm{N}_{2}$ was kept at $20 \mathrm{sccm}$.

\subsection{Neutron reflectometry measurements of Ti/TiN bilayers}

Neutron reflectometry (NR) measurements on the Ti/TiN bilayer samples were carried out using Asterix, a time-of-flight (ToF) instrument at the Lujan Neutron Scattering Center, Los Alamos National Laboratory [42]. Reflectivity, $R\left(Q_{\mathrm{z}}\right)$, is defined as the ratio of the intensity of the reflected beam to the incident beam and is a function of the neutron momentum transfer vector $Q_{z}$, where $Q_{z}=4 \pi \sin (\theta) / \lambda, \theta$ is the angle of incidence of the beam, and $\lambda$ is the wavelength of the neutron. In our ToF NR measurements, the neutron wavelengths ranged from 4.5 to $13 \AA$. For the data presented in this article, NR for the entire $Q_{z}$-range was covered by measurements performed at 4 different angles of incidence (i.e., $\sim 0.5, \sim 1.0, \sim 2.0$ and $4.0^{\circ}$ ), and the reflectivity curves were combined together. 
The specular scattering, averaged over the area of the neutron beam footprint $\left(\sim 500 \mathrm{~mm}^{2}\right)$, was analyzed to extract the scattering length density (SLD) profile as a function of depth from the sample surface.

Knowing the SLD profile as a function of depth, information about the thickness, density, chemical composition and roughness of each layer and interface in the sample may be extracted. Unlike in the case of x-rays, the coherent neutron scattering length, $b$, is not a monotonic function of the atomic number [43] of elements. The value of $b$ for Ti is negative $\left(b_{\mathrm{Ti}}=-3.438 \cdot 10^{-5} \AA\right)$ which, using a density of $\rho=4.506 \mathrm{~g} / \mathrm{cm}^{3}$, leads to a negative $\operatorname{SLD}_{\mathrm{Ti}}$ for the pure material of $-1.91 \cdot 10^{-6} \AA^{2}$. On the other hand, due to the high value of $b_{\mathrm{N}}\left(b_{\mathrm{N}}=9.36 \cdot 10^{-5} \AA\right)$, the SLD of $\operatorname{TiN}\left(\rho=5.22 \mathrm{~g} / \mathrm{cm}^{3}\right)$ is positive and equal to $\mathrm{SLD}_{\mathrm{TiN}}=3.04 \cdot 10^{-6} \AA^{-2}$. For comparison, the calculated $\mathrm{x}$-ray SLDs for Ti and TiN are $3.55 \cdot 10^{-5} \AA^{-2}$ and $4.19 \cdot 10^{-5} \AA^{-2}$, respectively providing much smaller scattering contrast and limiting the sensitivity of $\mathrm{x}$-rays to study interfacial structure between the two materials. Therefore the high neutron scattering contrast between $\mathrm{Ti}$ and $\mathrm{TiN}$ provides excellent opportunity to study the structural properties of nano-laminate bilayers and address the structure of the interfaces between them with $\AA$ precision. However, the combination of neutron and x-ray reflectometry could also be used to further reduce the uncertainty in the calculation of the $\operatorname{TiN}_{\mathrm{x}}$ stoichiometry [44].

\subsection{NR data interpretation and uncertainty estimation}

Analysis of $R$ vs. $Q_{z}$ provides a model of the SLD distribution normal to the sample surface. The NR measurement and data modeling procedures have been detailed 
elsewhere $[45,46]$. Here, NR data are presented multiplied by $Q_{z}^{4}$ to compensate for the power-of-four decrease of scattering with the momentum transfer vector, $Q_{z}$. Modeling of the SLD was performed using an open-source reflectivity package, MOTOFIT, which approximates the continuous SLD function by a number of layers each parameterized using a thickness and a constant SLD [47]. Interfacial roughness was described as an error function centered between two adjacent interfaces. Using the Abeles matrix formalism, Levenberg-Marquardt nonlinear least-square methods were employed to obtain the best fits with the lowest $\chi^{2}$ values and structurally meaningful parameters [48]. We used the simplest, physically meaningful description of the $\mathrm{Si} / \mathrm{SiO}_{\mathrm{x}} / \mathrm{Ti} / \mathrm{TiN} \mathrm{N}_{\mathrm{x}}$ system. In all cases, the parameters describing the $\mathrm{Si}$ substrate and native oxide $\left(\mathrm{SiO}_{\mathrm{x}}\right)$ layer on its surface were set to well established values and not allowed to vary during the fitting process. The $\mathrm{Si} \mathrm{SLD}$ of $2.07 \cdot 10^{-6} \AA^{-2}$ was used and all native $\mathrm{SiO}_{\mathrm{x}}$ layers were fixed to be $10 \AA$ thick with a SLD of $3.5 \cdot 10^{-6} \AA^{-2}$, which is in good agreement with previous studies [49]. Tabulated SLD values for bulk density $\mathrm{Ti}$ and TiN were used as starting parameters to refine the models of the composite film structures. Typical values for the error in layer thickness and scattering length densities were $+/-0.2 \AA$ and $0.1-0.2 \cdot 10^{-}$ ${ }^{6} \AA^{-2}$, respectively.

\section{RESULTS}

3.1 Ti/TiN bilayers - samples $A$ and B. Influence of increasing $N_{2}$ flow with constant sample bias. 
NR data, best-fit reflectivity curves, and corresponding SLD profiles for deposition procedures (Table 1) designed to produce a sharp interface $(A)$ and a graded interface $(B)$ are presented in Figure 1. The model parameters from the fits are summarized in Table 2. Sample $A$ was prepared in an attempt to produce the sharpest possible interface between the $\mathrm{Ti}$ and $\mathrm{TiN}_{\mathrm{x}}$ components. First $\sim 100 \AA$ of $\mathrm{Ti}$ was deposited with no $\mathrm{N}_{2}$ flow or bias applied to the sample for $50 \mathrm{sec}$ as described in Section 2.1. A second $\sim 100 \AA$ thick layer of $\mathrm{TiN}_{\mathrm{x}}$ was deposited on the first Ti layer by sputtering Ti for $50 \mathrm{sec}$ with $3 \mathrm{sccm} \mathrm{N}_{2}$ flow and a $20 \mathrm{~W}$ RF bias applied.

It is possible that a step-like increment in the $\mathrm{N}_{2}$ flow could create a diffuse (or graded) interface between the two components. With this in mind, sample $B$ was prepared using a similar method but the second $\mathrm{TiN}_{\mathrm{x}}$ deposition was divided into three 17 sec intervals with increasing $\mathrm{N}_{2}$ flow rates of 1,2 , and $3 \mathrm{sccm}$. As can be seen from Fig. 1 A, the two deposition protocols resulted in substantially different NR curves and different SLD distributions as shown in Fig.1 B. The fitted SLD parameters (Table 2) for the Ti and $\mathrm{TiN}_{\mathrm{x}}$ layers for sample $A$ and $B$ do not match the theoretical SLDs of pure Ti or TiN. One possible explanation for the discrepancy is that the average densities of the $\mathrm{Ti}$ and $\mathrm{TiN}$ in the thin films are 11 and $22 \%$ smaller than the bulk density values of the pure components. Another possibility is that there are additional nitrogen atoms in the $\mathrm{Ti}$ region and reduced nitrogen content in the TiN region (less than 1:1 stoichiometry). For nitrogen content below $\mathrm{TiN}_{0.5}$, the associated SLD was calculated by assuming a constant Ti unit cell volume and adding scattering contributions from additional nitrogen atoms in interstitial positions as needed. To calculate SLD for nitrogen content in excess of $\mathrm{TiN}_{0.5}$, 
the TiN unit cell volume was used and scattering contributions from nitrogen atoms were removed due to creation of vacancies. Using this approach, the SLD in the lower layer can be attributed to $\mathrm{TiN}_{0.05}$ and the SLDs of the top layer correspond to $\mathrm{TiN}_{0.85}$ and $\mathrm{TiN}_{0.91}$ for $A$ and $B$, respectively. The step-like increase of the $\mathrm{N}_{2}$ flow during the second deposition for sample $B$ resulted in a much broader interface between the two components. The $r m s$ roughness for the Ti/TiNx interface obtained for samples $A$ and $B$ were 10.5 and $15.7 \AA$ respectively (Table 2, Fig. 7). This demonstrates that the 1, 2, 3 sccm stepwise increase in nitrogen flow yielded a graded interface.

3.2 Ti/TiN bilayers - samples $C, D$ and $H$. Influence of sample bias and temperature under constant $N_{2}$ flow.

Figure 2 shows NR data from Ti/TiN bilayer samples along with best-fit curves and corresponding SLD profiles. The best-fit parameters are presented in Table 2. Samples $D$ and $H$ (Fig. 2, blue and red) were prepared at RT and slightly elevated temperature of $50^{\circ} \mathrm{C}$, respectively. In both cases, a $\sim 100 \AA \mathrm{Ti}$ layer was deposited similar to the previously discussed cases. Subsequently, three depositions of Ti with simultaneous $\mathrm{N}_{2}$ flow were made, each one lasting $50 \mathrm{sec}$ and aiming to obtain three $\sim 100 \AA$ thick $\mathrm{TiN}_{\mathrm{x}}$ layers. For both samples and each of the $\operatorname{TiN}_{\mathrm{x}}$ depositions the flow of the $\mathrm{N}_{2}$ followed the 1, 2, $3 \mathrm{sccm}$ scheme. Additionally, for sample $D$ a $20 \mathrm{~W}$ RF bias was applied during the three $\operatorname{TiN}_{\mathrm{x}}$ deposition steps while no bias was applied during the deposition of sample $H$. Both cases resulted in qualitatively similar NR data and SLD profiles (Fig. 2, blue and red symbols) exhibiting $\mathrm{TiN}_{\mathrm{x}}$ layers of similar properties: 372.1 vs. $344.6 \AA$ A thickness and 
SLDs of $2.44 \cdot 10^{-6} \AA^{-2} v s .2 .47 \cdot 10^{-6} \AA^{-2}$, respectively. The $r m s$ roughness parameters for the $\mathrm{Ti} / \mathrm{TiN}_{\mathrm{x}}$ interface were also similar with values of 21.1 and $22.3 \AA$, respectively (Table 2, Fig. 7). The biggest difference between the two cases was in the SLD of the underlying Ti layers: $-1.24 \cdot 10^{-6} \AA^{-2}$ for sample $D$ and $-1.90 \cdot 10^{-6} \AA^{-2}$ for sample $H$. While the SLD of this layer for sample $H$ matches that of pure Ti, the SLD of this layer for sample $D$ is significantly higher indicating either lower density of Ti or a substantial quantity of nitrogen interstitials intercalated in the Ti structure. The increased SLD of the underlying layer in sample $D$ can be attributed to a stoichiometry of $\mathrm{TiN}_{0.13}$. Since the SLD obtained from NR is not unique, this suggests that the applied bias of $20 \mathrm{~W}$ during the deposition of the subsequent $\operatorname{TiN}_{\mathrm{x}}$ layers is capable of driving nitrogen into the underlying Ti layer.

Sample $C$ was produced using the same $\mathrm{N}_{2}$ flow scheme of $1,2,3 \mathrm{sccm}$ during the deposition of the three $\operatorname{TiN}_{\mathrm{x}}$ layers as used for the previously discussed samples $D$ and $H$. However, all the depositions (including the initial Ti layer) were performed at $700^{\circ} \mathrm{C}$. The temperature had a very significant influence on the structure of both the $\mathrm{Ti}$ and $\mathrm{TiN}_{\mathrm{x}}$ layers and the interfacial region (Fig. 2, black symbols). The underlying layer was thicker $\left(245.1 \AA\right.$ ) and had an SLD of $-0.31 \cdot 10^{-6} \AA^{-2}$, significantly higher than that of pure Ti and consistent with a $\operatorname{TiN}_{0.31}$ stoichiometry. The thickness of the $\operatorname{TiN}_{\mathrm{x}}$ layer was only $210.3 \AA$ with an SLD of $2.58 \cdot 10^{-6} \AA^{-2}$, which, as in the previously discussed cases, can indicate $85 \%$ bulk TiN density or reduced nitrogen content. The high temperature applied during preparation resulted in a broader interfacial region with an rms roughness between the $\mathrm{Ti}$ and $\operatorname{TiN}_{\mathrm{x}}$ regions of $37.8 \AA$. Both the high SLD of the underlying layer and the 
broadening of the interface suggest that at $700^{\circ} \mathrm{C}$ nitrogen is capable of diffusing throughout the film during the $<5$ min deposition time.

3.3 Ti/TiN bilayers - samples $E$ and I. Influence of $\mathrm{N}^{2+}$ ion source with no bias to the sample and constant $N_{2}$ flow.

Samples $E$ and $I$ were prepared identically except for the orientation and power of the ion source used during the depositions of the $\mathrm{TiN}_{\mathrm{x}}$ layers. As before, a $\sim 100 \AA$ thick Ti layer was deposited followed by deposition of three $\sim 100 \AA$ thick $\mathrm{TiN}_{\mathrm{x}}$ layers. In these cases, significantly higher $\mathrm{N}_{2}$ flow rates of 5,10 and $20 \mathrm{sccm}$ were used with no bias applied to the sample. Sample $I$ was prepared at RT with no bias applied. The only variable was the $\mathrm{N}_{2}$ flow which was increased from 5 to $20 \mathrm{sccm}$ for the final $\operatorname{TiN}_{\mathrm{x}}$ layer. On the other hand, for sample $E$ a $150 \mathrm{~W}$ ion source was used to deliver ions roughly parallel to the substrate. Fig. 3 summarizes the NR and the SLD fitting results.

The SLD profiles obtained for $E$ and $I$ exhibit differences primarily in the SLD of the $\mathrm{TiN}_{\mathrm{x}}$ region. Thicknesses of the Ti layer for sample $E$ and $I$ were 92.2 and $106.3 \AA$, respectively with an SLD of $-1.9 \cdot 10^{-6} \AA^{-2}$, which corresponds to the SLD of fully dense bulk Ti. The thicknesses of the $\mathrm{TiN}_{\mathrm{x}}$ regions were also similar: 338.1 and $325.3 \AA$, with SLD values of $2.25 \cdot 10^{-6} \AA^{-2}$ and $2.51 \cdot 10^{-6} \AA^{-2}$, respectively. These SLDs correspond to $74 \%$ and $83 \%$ of the density of bulk TiN or, alternatively, the lower than predicted SLD may reflect reduced nitrogen content in the ceramic consistent with $\mathrm{TiN}_{0.82}$ and $\mathrm{TiN}_{0.88}$ stoichiometry. The combination of lower power and parallel orientation of the ion source 
yielded a small decrease in the nitrogen content within the $\mathrm{TiN}_{\mathrm{x}}$ region of the film. In both cases, the rms roughness of the interface between $\mathrm{Ti}$ and $\mathrm{TiN}_{\mathrm{x}}$ regions were small and equal to 5.0 and $7.0 \AA$ (Table 2, Fig. 7). This is comparable to the interfacial width of the sample engineered to have a sharp interface $(A)$.

3.4 Ti/TiN bilayers - samples $H$ and I. Influence of higher $N_{2}$ flow with no bias applied to the sample.

Here, we compare two previously discussed cases: samples $H$ and $I$. Sample $H$ was prepared at a slightly elevated temperature of $50^{\circ} \mathrm{C}$ and with $\mathrm{N}_{2}$ flow of 1,2 and $3 \mathrm{sccm}$ during the deposition of the $\mathrm{TiN}_{\mathrm{x}}$ regions. Sample $I$ was prepared using a slightly smaller deposition temperature $\left(25^{\circ} \mathrm{C}\right)$ and with an increased $\mathrm{N}_{2}$ flow of 5,10 and $20 \mathrm{sccm}$. Figure 4 summarizes the NR scattering and the corresponding best-fit SLD profiles.

The increase of $\mathrm{N}_{2}$ flow had significant influence on the SLD distribution of the interface (Table 1). Both deposition procedures resulted in the SLD of the Ti layer (154.5 and $106.3 \AA$ thick, respectively) of $-1.9 \cdot 10^{-6} \AA^{-2}$, which corresponds to the theoretical value of bulk Ti. The $\mathrm{TiN}_{\mathrm{x}}$ regions of thickness 344.6 and $325.3 \AA$ showed similar SLD values of 2.47 and $2.51 \cdot 10^{-6} \AA^{-2}$ approximately corresponding to either $82 \%$ of bulk TiN density or reduced nitrogen content consistent with a $\mathrm{TiN}_{0.88}$ stoichiometry. The lower 1,2 , and 3 sccm $\mathrm{N}_{2}$ flow applied during the preparation of sample $H$ resulted in a much more diffuse interface between the $\mathrm{Ti}$ and $\mathrm{TiN}_{\mathrm{x}}$ region. The rms roughness parameters for sample $H$ and $I$ were 22.3 and $7.0 \AA$ respectively (Fig.7). This suggests that the initial $\mathrm{N}_{2}$ flow of 5 sccm in sample $I$ caused immediate chemical reaction of $\mathrm{Ti}$ to the $\mathrm{TiN}_{\mathrm{x}}$ state without 
creating a graded interface.

3.5 Ti/TiN bilayers - samples $F$ and G. Comparison of deposition temperature ramp vs. applied bias for constant $N_{2}$ flow.

Sample $F$ was produced at room temperature, with a constant $3 \mathrm{sccm} \mathrm{N}_{2}$ flow rate and a stepwise increase in the applied sample bias of 5,10 and $20 \mathrm{~W}$ during the $\mathrm{TiN}_{\mathrm{x}}$ deposition (Table 1). The $\mathrm{TiN}_{\mathrm{x}}$ layer of sample $G$ was deposited using the same $\mathrm{N}_{2}$ flow but without any bias applied. Instead, a stepwise temperature ramp of 25,350 and $700^{\circ} \mathrm{C}$ was applied during the deposition of the $\mathrm{TiN}_{\mathrm{x}}$ layers. The NR spectra and resulting SLD profiles are shown in Fig. 5.

Sample $F$ had $\mathrm{Ti}$ and $\mathrm{TiN}_{\mathrm{x}}$ regions of 111.3 and $405.2 \AA$ in thickness with SLDs of $1.9 \cdot 10^{-6} \AA^{-2}$ and $2.57 \cdot 10^{-6} \AA^{-2}$, respectively. The SLD of Ti matched the theoretical bulk value while the $\mathrm{TiN}_{\mathrm{x}}$ region corresponded to either $85 \%$ density $\mathrm{TiN}$ or an average $\mathrm{TiN}_{0.89}$ stoichiometry. The low rms roughness of $9.3 \AA$ between the two layers was comparable to the interfacial width of the sample engineered to have a sharp interface (A). In sample $G$, the temperature ramp applied during $\mathrm{TiN}_{\mathrm{x}}$ deposition created a significantly different structure. Unlike all the previously discussed cases, the SLD distribution for sample $G$ cannot be described by a two-layer model. An additional third layer was required to properly describe the SLD distribution of the $\operatorname{TiN}_{\mathrm{x}}$ region (Table 2). Additionally, the SLD of the Ti layer was high $\left(0.82 \cdot 10^{-6} \AA^{-2}\right)$ and consistent with an average stoichiometry of $\mathrm{TiN}_{0.53}$ indicating a high degree of nitrogen diffusion into the underlying Ti layer. The SLD profile of the $\mathrm{TiN}_{\mathrm{x}}$ region exhibited two regions with either 
different density or stoichiometry. The layer adjacent to air had an SLD of $2.13 \cdot 10^{-6} \AA^{-2}$, which may correspond to either a $70 \%$ dense TiN layer or a $\mathrm{TiN}_{0.80}$ stoichiometry. On the other hand, the intermediate layer had an SLD of $3.33 \cdot 10^{-6} \AA^{-2}$, which is higher than the theoretical value for TiN suggesting the presence of excess nitrogen content in this region of the film.

\subsection{Ti/TiN bilayers - samples $J$ and $K$. Comparison of different post-processing} protocols.

Unlike all previously discussed cases, samples $J$ and $K$ were prepared as pure Ti layers and subsequently processed to introduce nitrogen. In both cases, $\sim 200 \AA$ thick layers of Ti were deposited at RT for $100 \mathrm{sec}$ with no bias applied. Afterwards, sample $J$ was exposed to 20 mTorr of pure $\mathrm{N}_{2}$ with an applied $20 \mathrm{~W}$ bias for $100 \mathrm{sec}$. Sample $K$ was processed without any bias but under $20 \mathrm{sccm} \mathrm{N}_{2}$ flow with a 7 minute ramp of temperature to $700^{\circ} \mathrm{C}$ and subsequent 15 minute treatment at $700^{\circ} \mathrm{C}$ with $10 \mathrm{mTorr}$ of $\mathrm{N}_{2}$. The two procedures resulted in vastly different SLD profiles. For sample $J$, a $31.4 \AA$ thick layer of $\operatorname{TiN}_{x}$ was formed preserving $175.9 \AA$ of dense, bulk-like Ti with an SLD of $1.90 \cdot 10^{-6} \AA^{-2}$ underneath. The $\mathrm{TiN}_{\mathrm{x}}$ layer had an SLD of $2.50 \cdot 10^{-6} \AA^{-2}$ corresponding to either $82 \%$ of the bulk density of $\mathrm{TiN}$ or a $\mathrm{TiN}_{0.87}$ stoichiometry. The rms roughness of the $\mathrm{Ti} / \mathrm{TiN}_{\mathrm{x}}$ interface was $6.1 \AA$ and the $\mathrm{TiN}_{\mathrm{x}} /$ air interface was also sharp with an $r m s$ roughness of $10.0 \AA$ (Fig. 7). The treatment of sample $K$ yielded a significantly different SLD distribution. The substrate adjacent region had an SLD of $-1.02 \cdot 10^{-6} \AA^{-2}$ consistent with $\mathrm{TiN}_{0.17}$ indicating significant nitrogen presence throughout the $\mathrm{Ti}$ film. On the air adjacent face of the film, an SLD of $1.57 \cdot 10^{-6} \AA^{-2}$ was obtained corresponding to a $\mathrm{TiN}_{0.69}$ 
stoichiometry. The simplest model to describe the SLD profile of the $\operatorname{TiN}_{\mathrm{x}}$ required two layers with high interfacial roughness values to yield a continuously changing SLD profile. This distribution represents a highly graded nitrogen distribution throughout the film (Fig. 7).

\section{DISCUSSION}

Using neutron reflectivity, the structural properties of $\mathrm{Ti} / \mathrm{TiN}_{\mathrm{x}}$ bilayers, including the average nitrogen content, were obtained as a function of depth with Å-level resolution. While this technique provided excellent resolution normal to the interface, it was insensitive to both the in-plane distribution of nitrogen and the crystallographic structure of various $\mathrm{Ti}$ and $\mathrm{TiN}_{\mathrm{x}}$ phases. In most cases the SLD of the $\mathrm{TiN}_{\mathrm{x}}$ regions were lower than that calculated for bulk density TiN. One possible explanation is a decreased density of TiN due to defects. However, since these layers appear to be uniform and consistent in structure across many sample preparations a more viable possibility is lower nitrogen content consistent with, for example, $\mathrm{TiN}_{0.9}$ structure [50]. The only case where reduced nitrogen content in the $\mathrm{TiN}_{\mathrm{x}}$ layer was not observed occurred when temperature was applied in a step-like manner $\left(\mathrm{RT}, 350\right.$ and $\left.700^{\circ} \mathrm{C}\right)$ during deposition $(G)$. This procedure resulted in a more complicated SLD profile (Fig. 5B, red line), where the $\mathrm{TiN}_{\mathrm{x}}$ film was composed of two distinct regions. The SLD of the layer created at $350^{\circ} \mathrm{C}$ was higher than the theoretical value for 1:1 TiN suggesting excess nitrogen (as interstitials). Although the experimental data for $\mathrm{TiN}_{1+\mathrm{x}}$ phases are not reported, the theoretically predicted

cesium chloride structure of TiN [51] would result in an SLD of $3.24 \cdot 10^{-6} \AA^{-2}$, close to 
the observed value.

Samples $A$ and $B$ provide proof of principle evidence that the proper control of magnetron sputtering deposition conditions can be used to tune the nitrogen distribution across a $\mathrm{Ti} / \mathrm{TiN}_{\mathrm{x}}$ interface from sharp to graded. This can be clearly seen by comparing the full width half maxima (FWHM) of the Gaussian distributions obtained by taking the derivative of the SLD profiles (Fig. 7A). Building from this finding, we performed a series of studies to explore the role of several different deposition parameters and postprocessing protocols on the structure of $\mathrm{Ti} / \mathrm{TiN}_{\mathrm{x}}$ composite films. The nitrogen distributions as a function of depth in the resulting structures can be attributed to two mechanisms: $(i)$ control of nitrogen and titanium co-deposition rates and (ii) control of nitrogen penetration into underlying titanium.

\subsection{Control of nitrogen and titanium co-deposition rate.}

Of all the parameters explored, nitrogen flow proved most relevant for controlling the relative quantities of nitrogen and titanium during co-deposition. Comparison of preparation protocols for samples $H$ and $I$ clearly indicate that the lower step-wise $\mathrm{N}_{2}$ flow rates can be used to create a graded interface. $\mathrm{N}_{2}$ flow above a certain threshold $(\geq 5$ sccm) quickly saturated the $\operatorname{TiN}_{\mathrm{x}}$ phase formation and created a sharp interface. However, decreased $\mathrm{N}_{2}$ flow rates yielded a large FWHM increase of the SLD derivative while still maintaining the initial underlying Ti structure (Fig. 7D). Saturation with nitrogen may occur at much smaller flow rates than $5 \mathrm{sccm}$. Inspection of Figure 4B shows that the 
graded interface persists between $100 \AA$ and $200 \AA$ when a flow rate of $1 \mathrm{sccm}$ was used and the saturated $\mathrm{TiN}_{\mathrm{x}}$ phase was formed immediately afterwards at a flow rate of 2 sccm. Considering this, a similar deposition protocol using smaller $\mathrm{N}_{2}$ flow rates may be capable of producing significantly more diffuse $\mathrm{Ti} / \mathrm{TiN}_{\mathrm{x}}$ interfaces. Importantly, the use of nitrogen flow to control the co-deposition of nitrogen and titanium did not impact the structure or nitrogen content of the underlying Ti layers providing a distinct advantage to this mechanism for creating graded $\mathrm{Ti} / \mathrm{TiN}_{\mathrm{x}}$ interfaces.

\subsection{Nitrogen penetration into underlying titanium}

For all samples studied, the same deposition parameters were used to deposit the underlying Ti layer. In many cases, the SLD of this layer matched $(E, F, H, I, J)$ or was extremely close to $(A, B)$ the value corresponding to bulk Ti $\left(-1.9 \cdot 10^{-6} \AA^{-2}\right)$. For the remaining samples $(C, D, G, K)$, the underlying $\mathrm{Ti}$ layers exhibited significantly increased SLDs. Based on the NR measurements alone, the differences may be attributed to either a decreased $\mathrm{Ti}$ density or the inclusion of nitrogen. However, since all of the $\mathrm{Ti}$ depositions were identical, it is likely that the increased SLDs were caused by the subsequent $\operatorname{TiN}_{\mathrm{x}}$ depositions or post-processing in a nitrogen rich environment. This suggests that, for the cases where a higher SLD of the underlying layer was determined, the increase can most likely be attributed to nitrogen penetrating into the underlying layer during the subsequent deposition or processing steps.

The implications of nitrogen penetration on the film structure are most clearly shown by 
the different post-processing of Ti samples $J$ and $K$. When a 20W RF bias was applied $(J)$ to drive nitrogen ions towards the sample, a well-defined $\mathrm{TiN}_{\mathrm{x}}$ layer was formed on the surface with a sharp interface between the $\operatorname{TiN}_{x}$ and Ti. Presumably, the kinetic energy imparted to the ions by the $20 \mathrm{~W}$ bias was sufficient to penetrate $30 \AA$ into the Ti layer but no deeper. This suggests that changing the magnitude of the bias may be used to control the thickness of the $\operatorname{TiN}_{\mathrm{x}}$ layer but the resulting interfacial structure will remain sharply defined because the kinetic energy of the nitrogen ions limits their penetration depth. In the case of $700^{\circ} \mathrm{C}$ elevated temperature $(K)$, the likely mechanism for nitrogen penetration into the $\mathrm{Ti}$ is diffusion. While an applied bias delivered a limited kinetic energy to the nitrogen ions, high temperature provided a continuous source of energy to the nitrogen atoms throughout the $900 \mathrm{sec}$. processing period. The differences between these two mechanisms are striking: as opposed to the sharply defined $\operatorname{TiN}_{\mathrm{x}}$ layer, temperature driven diffusion resulted in a nitrogen gradient throughout the $200 \AA$ Ti layer and a highly diffuse interface (Fig. 7, F). Interestingly, after processing at elevated temperature the maximum SLD at the air interface of the film was significantly smaller than the $\operatorname{TiN}_{\mathrm{x}}$ layer created using an applied bias. While the kinetic implantation of nitrogen ions yielded an average stoichiometry of approximately $\operatorname{TiN}_{0.87}$ at the surface, a maximum of only $\mathrm{TiN}_{0.69}$ was obtained using the high temperature processing. This suggests that a nitrogen diffusion mechanism alone is insufficient to create a high nitrogen content $\mathrm{TiN}_{\mathrm{x}}$ layer.

Bias applied during the $\operatorname{TiN}_{\mathrm{x}}$ deposition steps also resulted in nitrogen penetration into the underlying Ti layer. For sample $D$, a constant $20 \mathrm{~W}$ RF bias was applied throughout 
all three $\mathrm{TiN}_{\mathrm{x}}$ deposition steps and the nitrogen content of the underlying Ti layer increased to an average stoichiometry of $\mathrm{TiN}_{0.13}$. Since $\mathrm{TiN}_{\mathrm{x}}$ was being deposited simultaneously with the applied bias, the relatively low quantity of nitrogen may be ascribed to the shorter time that the Ti surface was exposed to ion implantation. Further, we expected that the nitrogen penetration depth would be limited to $30 \AA$ as observed in the post-processed sample. To model this, we subdivided the underlying Ti into two layers with the lower layer having the SLD of bulk $\mathrm{Ti}$ and the upper layer with an increased SLD. However, the quality of the fit was not improved by this approach so we were unable to determine the nitrogen penetration depth with a sufficient degree of confidence. For sample $F$, a RF bias ramp was applied increasing from 5 to 10 to $20 \mathrm{~W}$ during the three $\mathrm{TiN}_{\mathrm{x}}$ deposition steps. In this case, no penetration of nitrogen into the underlying Ti was observed. This indicates that the initial $5 \mathrm{~W}$ bias provided insufficient kinetic energy for ion implantation and that the deposition of $\operatorname{TiN}_{x}$ during this first step covered the Ti surface preventing nitrogen penetration by the higher applied biases.

Nitrogen penetration into the underlying Ti layer was also observed when a constant elevated temperature of $700^{\circ} \mathrm{C}(C)$ and a temperature ramp of $\mathrm{RT}, 350,700^{\circ} \mathrm{C}(G)$ were applied during the $\mathrm{TiN}_{\mathrm{x}}$ deposition. At constant temperature, nitrogen diffused throughout the underlying $100 \AA$ Ti layer reaching the equivalent of a $\mathrm{TiN}_{0.31}$ stoichiometry. Relative to the post-processed sample, the higher nitrogen content of the underlying layer may be ascribed to a combination of a shorter diffusion distance (100§ vs. $200 \AA$ Ti thickness) and higher nitrogen concentration in the deposition chamber. Nitrogen diffusion during the deposition process also resulted in a highly graded interface compared to samples 
prepared at RT (Fig. 7, B). Nitrogen also diffused throughout the underlying Ti layer when a temperature ramp was applied. Interestingly, the nitrogen content was significantly higher, equivalent to $\mathrm{TiN}_{0.53}$, despite the fact that the sample was exposed to less extensive thermal treatment. This discrepancy is likely related to the higher nitrogen flow rate used during the temperature ramp deposition.

\section{CONCLUSION.}

Neutron reflectometry characterization of $\mathrm{Ti} / \mathrm{TiN}$ metal-ceramic composites was used to investigate the flexibility of magnetron sputtering techniques to tune the structure and properties of interfaces within the material. Such control over the interfacial structures within these materials can be exploited to improve various material properties such as fracture toughness and hardness. Elevated temperatures applied during or after $\mathrm{TiN}_{\mathrm{x}}$ deposition created very diffuse interfaces between the $\mathrm{Ti}$ and $\mathrm{TiN}_{\mathrm{x}}$ films. However, this method always led to significant diffusion of nitrogen into the underlying $\mathrm{Ti}$ Nevertheless, proper manipulation of temperature, processing time and the partial pressure of $\mathrm{N}_{2}$ should allow for the creation of graded interfaces without compromising the underlying $\mathrm{Ti}$ properties. An alternative strategy for the formation of graded interfaces involves the control of $\mathrm{N}_{2}$ flow to vary the stoichiometry of $\mathrm{TiN}_{\mathrm{x}}$ during the codeposition. The advantage of this method is that the properties and structure of the underlying $\mathrm{Ti}$ is unperturbed by the process. 


\section{ACKNOWLEDGEMENTS}

The authors gratefully acknowledge support from the U.S. Department of Energy, Office of Science, Office of Basic Energy Sciences. This work was performed, in part, at the Center for Integrated Nanotechnologies, an Office of Science User Facility operated for the U.S. Department of Energy (DOE) Office of Science. Los Alamos National Laboratory, an affirmative action equal opportunity employer, is operated by Los Alamos National Security, LLC, for the National Nuclear Security Administration of the U.S. Department of Energy under Contract DE- AC52-06NA25396. This work also benefited from the use of the Lujan Neutron Scattering Center at LANSCE.

\section{Figure captions:}

Fig. 1. (A) NR data from sample $A$ and $B$ (black and red circles, respectively). The error bars denote the standard deviation for each NR measurement and curves are shifted vertically for clarity. The black and red solid lines are the fits corresponding to the lowest $\chi^{2}$ values and the SLD profiles shown in (B). The fitting parameters are listed in Table 1. $z=0$ defines the $\mathrm{Si} / \mathrm{SiO}_{\mathrm{x}}$ interface. The regions of low and high SLDs in (B) correspond to the $\mathrm{Ti}$ and $\mathrm{TiN}_{\mathrm{x}}$ regions, respectively.

Fig. 2. (A) NR data from sample $C, D$, and $H$ (black, blue and red circles, respectively). The error bars denote the standard deviation for each NR measurement and curves are shifted vertically for clarity. The black, blue, and red solid lines are the fits corresponding

to the lowest $\chi^{2}$ values and the SLD profiles shown in (B). The fitting parameters are 
listed in Table 1. $z=0$ was placed at the $\mathrm{Si} / \mathrm{SiO}_{\mathrm{x}}$ interface. The regions of low and high SLDs in (B) correspond to $\mathrm{Ti}$ and $\mathrm{TiN}_{\mathrm{x}}$ regions, respectively.

Fig. 3. (A) NR data from sample $E$ and $I$ (red and black circles, respectively). The error bars denote the standard deviation for each NR measurement and curves are shifted vertically for clarity. The red and black solid lines are the fits corresponding to the lowest $\chi^{2}$ values and the SLD profiles shown in (B). The fitting parameters are listed in Table 1. $z=0$ was placed at the $\mathrm{Si} / \mathrm{SiO}_{\mathrm{x}}$ interface. The regions of low and high SLDs in (B) correspond to $\mathrm{Ti}$ and $\mathrm{TiN}_{\mathrm{x}}$ regions, respectively.

Fig. 4. (A) NR data from sample $H$ and $I$ (red and black circles, respectively). The error bars denote the standard deviation for each NR measurement and curves are shifted vertically for clarity. The red and black solid lines are the fits corresponding to the lowest $\chi^{2}$ values and the SLD profiles shown in (B). The fitting parameters are listed in Table 1. $z=0$ was placed at the $\mathrm{Si}_{/} \mathrm{SiO}_{\mathrm{x}}$ interface. The regions of low and high SLDs in (B) correspond to Ti and $\mathrm{TiN}_{\mathrm{x}}$ regions, respectively.

Fig. 5. (A) NR data from sample $F$ and $G$ (black and red circles). The error bars denote the standard deviation for each NR measurement and curves are shifted vertically for clarity. The red and black solid lines are the fits corresponding to the lowest $\chi^{2}$ values and the SLD profiles shown in (B). The fitting parameters are listed in Table $1 . z=0$ was placed at the $\mathrm{Si} / \mathrm{SiO}_{\mathrm{x}}$ interface. The regions of low and high SLDs in (B) correspond to $\mathrm{Ti}$ and $\mathrm{TiN}_{\mathrm{x}}$ regions, respectively. 
Fig. 6. (A) NR data from sample $J$ and $K$ (black and red circles). The error bars denote the standard deviation for each NR measurement and curves are shifted vertically for clarity. The red and black solid lines are the fits corresponding to the lowest $\chi^{2}$ values and the SLD profiles shown in (B). The fitting parameters are listed in Table 1. $z=0$ was placed at the $\mathrm{Si} / \mathrm{SiO}_{\mathrm{x}}$ interface. The regions of low and high SLDs in (B) correspond to $\mathrm{Ti}$ and $\mathrm{TiN}_{\mathrm{x}}$ regions, respectively.

Fig. 7. $d(S L D(z)) / d z$ derivatives of the SLD profiles around the main Ti/TiN $\mathrm{x}_{\mathrm{x}}$ interface. The SLDs were obtained from fitting the NR data shown in Figures 1-6. The center of each $\mathrm{Ti} / \mathrm{TiN}_{\mathrm{x}}$ interface was placed at $z=0$. Since interfacial roughnesses were described by error functions, their derivatives are Gaussians with rms proportional to the width of the $\mathrm{Ti} / \mathrm{TiN}_{\mathrm{x}}$ interfaces. Panels A-F corresponds to the bilayer preparation procedures described in the paragraphs $3.1-3.6$.

\section{REFERENCES}

[1] I. J. Beyerlein, M. J. Demkowicz, A. Misra, and B. P. Uberuaga, Defect-Interface Interactions. Progress in Materials Science. 74 (2015) 125-210.

[2] W.Z. Han, M.J. Demkowicz, N.A. Mara, E.G. Fu, S. Sinha, A.D. Rollett, et al, Design of radiation tolerant materials via interface engineering. Advanced Materials. 25 (2013) 6975-9.

[3] K.M. Knowles, The dislocation geometry of interphase boundaries. Philos Mag A. 46 (1982) 951-69.

[4] R.W. Siegel, S.M. Chang, R.W. Balluffi, Vacancy loss at grain boundaries in quenched polycrystalline gold. Acta Metallurgica. 28 (1980) 249-257 
[5] T. Nizolek, I. J. Beyerlein, N. A. Mara, J. T. Avallone, T. M. Pollock, Tensile Behavior and Flow Stress Anisotropy of Accumulative Roll Bonded $\mathrm{Cu}-\mathrm{Nb}$ Nanolaminates. Applied Physics Letters. 108 (2016) 051903.

[6] T. Nizolek, N. A. Mara, I. J. Beyerlein, J. T. Avallone, T. M. Pollock, Enhanced Plasticity via kinking in cubic metallic nanolaminates. Advanced Engineering Materials. 17 (2015) 781-785.

[7] E. Martínez, B. P. Uberuaga, I. J. Beyerlein, Interaction of small, mobile stacking fault tetrahedra with free surfaces, dislocations and interfaces in $\mathrm{Cu}$ and $\mathrm{Cu}-\mathrm{Nb}$. Physical Review B. 93 (2016) 054105.

[8] E. Martinez, A. Caro, I. J. Beyerlein, Atomistic modeling of defect-induced plasticity in $\mathrm{CuNb}$ nanocomposites. Phys. Rev. B. 90 (2014) 054103.

[9] N.A. Mara and I.J. Beyerlein, Review: Effect of bimetal interface structure on the mechanical behavior of $\mathrm{Cu} / \mathrm{Nb}$ nano-layered composites. Journal of Materials Science $\mathrm{A}$. 49 (2014) 6497-6516.

[10] S. J. Zheng, J. S. Carpenter, R. J. McCabe, and N. A. Mara, Engineering interface structures and thermal stabilities via SPD processing in bulk nanostructured metals. Scientific Reports. 4 (2014) 4226.

[11] S. J. Zheng, I.J. Beyerlein, J. S. Carpenter, K. Kang, J. Wang, W. Z. Han, and N. A. Mara, High strength and thermally stable bulk nanolayered composites due to twininduced interfaces. Nature Communications. 4 (2013) 1696.

[12] L.E. Toth. Transition metal carbides and nitrides, Elsevier, 2014.

[13] H. Ljungcrantz, M. Odén, L. Hultman, J. Greene, J.E. Sundgren, Nanoindentation studies of single-crystal (001)-, (011)-, and (111)- oriented TiN layers on MgO. J. Appl. Phys. 80 (1996) 6725-6733

[14] S.Q. Wang, I. Raaijmakers, B.J. Burrow, S. Suthar, S. Redkar, K.B. Kim, Reactively sputtered TiN as a diffusion barrier between $\mathrm{Cu}$ and Si. J. Appl. Phys. 68 (1990) 51765187

[15] J. Narayan, W. Fan, R. Narayan, P. Tiwari, H. Stadelmaier, Diamond, diamond-like and titanium nitride biocompatible coatings for human body parts. Materials Science and Engineering: B. 25 (1994) 5-10

[16] M. Marlo, V. Milman, Density-functional study of bulk and surface properties of titanium nitride using different exchange-correlation functionals. Physical Review B. 62 (2000) 2899-2907 
[17] M. Larsson, M. Bromark, P. Hedenqvist, S. Hogmark, Depostion and mechanical properties of multilayers PVD Ti-TiN coatings. Surface and Coatings Technology. 76 (1995) 202-205

[18] A. Leyland, A. Matthews, Thick Ti/TiN multilayered coatings for abrasive and erosive wear-resistance. Surface and Coatings Technology. 70 (1994) 19-25

[19] E. Bemporad, M. Sebastiani, C. Pecchio, S. De Rossi, High thickness Ti/TiN multilayer thin coatings for wear resistant applications. Surface and Coatings Technology. 201 (2006) 2155-2165

[20] Z.D. Cui, S.L Zhu, H.C. Man, X.J. Yang, Microstructure and wear performance of gradient $\mathrm{Ti} / \mathrm{TiN}$ metal matrix composite coating synthesized using a gas nitriding technology. Surface and Coatings Technology. 190 (2005) 309-313

[21] K.J. Ma, A. Bloyce, T. Bell, Examination of mechanical properties and failure mechanisms of TiN and Ti-TiN multilayer coatings. Surface and Coatings Technology. 76 (1995) 297-302

[22] M. Herranen, U. Wiklund, J.O. Carlsson, S. Hogmark, Corrosion behaviour of Ti/TiN multilayer coated tool steel. Surface and Coatings Technology. 99 (1998) 191-196

[23] L. Chenglong, Y. Dazhi, L. Guoqiang, Q. Min, Corrosion resistance and hemocompatibility of multilayered Ti/TiN-coated surgical AISI 316L stainless steel. Materials Letters. 59 (2005) 3813-3819

[24] J. Olowolafe, R. Jones Jr, A.C. Campbell, R. Hegde, C. Mogab, R.J. Gregory, Effects of anneal ambients and Pt thickness on Pt/Ti and Pt/Ti/TiN interfacial reactions. Appl. Phys. 73 (1993) 1764-1772

[25] M. Mändl, H. Hoffmann, P.J. Kücher, Diffusion barrier properties of Ti/TiN investigated by transmission electron-microscopy. Appl. Phys. 68 (1990) 2127-2132

[26] S. Pathak et al., On the origins of hardness of $\mathrm{Cu}-\mathrm{TiN}$ nano layered composites. Scripta Materialia. 109 (2015) 48-51

[27] M. Oden, H. Ljungcrantz, L. Hultman. Characterization of the induced plastic zone in a single crystal $\mathrm{TiN}(001)$ film by nanoindentation and transmission electron microscopy. J. Mater. Res. 12 (1997) 2134

[28] A.M. Minor, et al., In situ nanoindentation of epitaxial TiN/MgO (001) in a transmission electron microscope. J. Elec. Mater. 32 (2003) 1023

[29] D. Bhattacharyya, et al., Compressive flow behavior of Al-TiN multilayers at nanometer scale layer thickness. Acta Mater. 59 (2011) 3804 
[30] N. Li, H. Wang, A. Misra, J. Wang, In situ nanoidentation study of platic codeformation in Al-TiN nanocompostites. Scientific Reports. 4 (2014) 6633

[31] M.B. Daia, P. Aubert, S. Labdi, C. Sant, F.A. Sadi, P. Houdy, J.L. Bozet, Nanoindentation investigation of Ti/TiN multilayer films. J. Appl. Phys. 87 (2000) 7753.

[32] A. Dück, N. Gamer, W. Gesatzke, M. Griepentrog, W. Österle, M. Sahre, I. Urban, Ti/TiN multilayer coatinds: deposition technique, characterization and mechanical properties. Surface and Coatings Technology. 142 (2001) 579-584

[33] E. Kusano, M. Kitagawa, H. Nanto, A. Kinbara, Hardness enhancement by compositionally modulated structure of Ti/TiN multilayer films. Journal of Vacuum Science \& Technology A. 16 (1998) 1272-1276

[34] K. Shih, D. Dove, Ti/Ti-N Hf/Hf-N and W/W-N multilayer films with high mechanical hardness. Appl. Phys. Lett. 61 (1992) 654-656

[35] S.J. Bull, A.M. Jones, Multilayer coatings for improved performance. Surface and Coatings Technology. 78 (1996) 173-184

[36] M.C. Simmonds, H. Van Swygenhoven, E. Pflüger, A. Savan, R. Hauert, L. Knoblauch, S. Mikhailov, Magnetron sputter deposition and characterisation of Ti/TiN, $\mathrm{Au} / \mathrm{TiN}$ and MoSx/Pb multilayers. Surface and Coatings Technology. 94 (1997) 490-494

[37] X.W. Zhou, H.N.G. Wadley, R.A. Johnson, D.J. Larson, N. Tabat, A. Cerezo, A.K. Petford-Long, G.D. W. Smith, P.H. Clifton, R.L. Martens, T.F. Kelly, Atomic scale structure of sputtered metal multilayeres, Acta Mater. 49 (2001) 4005-4015

[38] J. A. Sprague and C. M. Gilmore, Molecular dynamics simulations of film-substrate interface mixing in the energetic deposition of fcc metals, Thin Solid Films 272 (1996) $244-254$

[39] S.P. Kim, S.C. Lee, K.R. Lee, Y.C. Chung, Atomic mixing behavior of $\mathrm{Co} / \mathrm{Al}(001)$ vs. Al/fcc-Co(001): molecular dynamics simulation, J. Electroceramics. 13 (2004) 315320

[40] X.W. Zhou, R.A. Johnson, H.N.G. Wadley, Misfit-energy-increaseing dislocations in vapor-deposited CoFe/NiFe multilayers, Phys. Rev. B 69 (2004) 114113

[41] Z. Erdelyi, I.A. Szabo, D.L. Beke, Interface sharpening instead of broadening by diffusion in ideal binary alloys, Phys. Rev. Lett. 89 (2002) 165901

[42] M.R. Fitzsimmons and C.F. Majkrzak, Application of polarized neutron reflectometry to studies of artificially structured magnetic materials, in: Y. Zhu, Modern Techniques for Characterizing Magnetic Materials, Kluwer, Boston 2005, pp. 107-152. 
[43] V.F. Sears, Thermal-Neutron Scattering Lengths and Cross Sections for CondensedMatter Research, Atomic Energy of Canada Limited Report AECL-8490 (1984)

[44] S. Singh, S. Basu, M. Gupta, C. F. Majkrzak, and P. A. Kienzle, Growth kinetics of intermetallic alloy phase at the interfaces of a $\mathrm{Ni} / \mathrm{Al}$ multilayer using polarized neutron and x-ray reflectometry, Phys. Rev. B 81, 235413 (2010).

[45] O.S. Heavens, Optical Properties of Thin Solid Films, Courier Dover Publications, 1955.

[46] M. Zhernenkov, M.S. Jablin, A. Misra, M. Nastasi, Y.Q. Wang, M.J. Demkowicz, J.K. Baldwin, and J. Majewski, Trapping of implanted $\mathrm{He}$ at $\mathrm{Cu} / \mathrm{Nb}$ interfaces measured by neutron reflectometry, Appl. Phys. Lett. 98 (2011) 241913

[47] A. Nelson, Co-refinement of multiple-contrast neutron/X-ray reflectivity data using MOTOFIT, J. Appl. Cryst. 39 (2006) 273-276

[48] F. Abelès, La theorie generale des couches minces, J. Phys. Radium. 11 (1950) 307309

[49] M. Morita, T. Ohmi, E. Hasegawa, M. Kawakami, M. Ohwada, Growth of native oxide on a silicon surface, J. Appl. Phys. 68 (1990) 1272

[50] A.N. Christensen, The temperature factor parameters of some transition metal carbides and nitrides by single crystal X-ray and neutron diffraction, Acta Chemica Scandinavica, Series A. 32 (1978) 89-90

[51] Z.T.Y. Liu, X. Zhou, S.V. Khare, D. Gall, Structural, mechanical and electronic properties of $3 \mathrm{~d}$ transition metal nitrides in cubic zincblende, rocksalt and cesium chloride structures: a first-principles investigation, Journal of Physics: Condensed Matter. 26 (2014) 025404-1 
Table 1.

\begin{tabular}{|c|c|c|c|c|c|c|}
\hline Sample & $\begin{array}{c}\text { Temperature } \\
{\left[{ }^{\circ} \mathrm{C}\right]}\end{array}$ & $\begin{array}{c}\mathrm{Ti} \\
\text { thickness } \\
{[\AA ̊]}\end{array}$ & $\begin{array}{c}\mathrm{TiN}_{\mathrm{x}} \\
\text { thickness } \\
{[\AA \AA]}\end{array}$ & $\begin{array}{c}\mathrm{N}_{2} \text { flow or pressure } \\
{[\mathrm{sccm}]}\end{array}$ & $\begin{array}{c}\text { Sample bias } \\
\text { or ion source } \\
\text { [W] }\end{array}$ & $\begin{array}{c}\text { Time } \\
{[\mathrm{s}]}\end{array}$ \\
\hline$A$ & $\mathrm{RT}, \mathrm{RT}$ & 100 & 100 & 0,3 & 0,20 & 50,50 \\
\hline$B$ & $\mathrm{RT}, \mathrm{RT}, \mathrm{RT}, \mathrm{RT}$ & 100 & $3 \times 33$ & $0,1,2,3$ & $0,20,20,20$ & $50,17,17,17$ \\
\hline$C$ & $700,700,700,700$ & 100 & $3 \times 100$ & $0,1,2,3$ & $0,0,0,0$ & $50,50,50,50$ \\
\hline$D$ & $\mathrm{RT}, \mathrm{RT}, \mathrm{RT}, \mathrm{RT}$ & 100 & $3 \times 100$ & $0,1,2,3$ & $0,20,20,20$ & $50,50,50,50$ \\
\hline$E$ & $\mathrm{RT}, \mathrm{RT}, \mathrm{RT}, \mathrm{RT}$ & 100 & $3 \times 100$ & $0,5,10,20$ & $\begin{array}{l}0,0,0,0 \\
150 \mathrm{~W}, \text { parallel to } \\
\text { substrate }\end{array}$ & $50,50,50,50$ \\
\hline$F$ & RT, RT, RT, RT & 100 & $3 \times 100$ & $0,3,3,3$ & $0,5,10,20$ & $50,50,50,50$ \\
\hline$G$ & RT, RT, 350, 700 & 100 & $3 \times 100$ & $0,3,3,3$ & $0,0,0,0$ & $50,50,50,50$ \\
\hline$H$ & $50,50,50,50$ & 100 & $3 \times 100$ & $0,1,2,3$ & $0,0,0,0$ & $50,50,50,50$ \\
\hline$I$ & RT, RT, RT, RT & 100 & $3 \times 100$ & $0,5,10,20$ & $0,0,0,0$ & $50,50,50,50$ \\
\hline$J$ & RT & 200 & & $\begin{array}{l}0,20 \mathrm{mTorr} \text { of } \mathrm{N}_{2} \\
\text { no } \mathrm{Ar}\end{array}$ & $\begin{array}{l}0 \text { during Ti deposition, } \\
20 \text { during } \mathrm{N}_{2} \text { treatment }\end{array}$ & $100,100^{a}$ \\
\hline$K$ & $\begin{array}{l}\text { RT, ramp to } 700, \\
700\end{array}$ & 200 & & $\begin{array}{l}20 \text { for T ramp and } \\
10 \text { mTorr for } 900 \mathrm{sec}\end{array}$ & 0 & $\begin{array}{l}100,420 \text { for } \mathrm{T} \\
\text { ramp, } 900\end{array}$ \\
\hline
\end{tabular}

a.Processing time with $\mathrm{N}_{2}$.

b. Thicknesses reflect the expected values obtained from previous profilometry measurements of similar depositions. The exact thickness values were verified by NR measurements (see text). 
Table 2.

\begin{tabular}{|c|c|c|c|c|c|c|c|c|c|c|}
\hline \multirow[t]{2}{*}{ Sample } & \multirow{2}{*}{$\begin{array}{c}\text { Ti layer } \\
\text { thicknes } \\
s \\
{[\AA]} \\
{[\AA]}\end{array}$} & \multirow{2}{*}{$\begin{array}{c}\text { Ti layer } \\
\text { SLD } \\
{\left[10^{-6} \AA^{-2}\right]}\end{array}$} & \multicolumn{2}{|c|}{$\begin{array}{c}\text { TiN }_{\mathrm{x}} \text { thickness } \\
{[\AA \AA]}\end{array}$} & \multicolumn{2}{|c|}{$\begin{array}{c}\text { TiN }_{\mathrm{x}} \text { layers SLD } \\
{\left[10^{-6} \AA^{-2}\right]}\end{array}$} & \multicolumn{3}{|c|}{$\begin{array}{c}\text { rms roughness } \\
[\AA]]\end{array}$} & \multirow[t]{2}{*}{$x^{2}$} \\
\hline & & & & & & & $\mathrm{Ti} / \mathrm{TiN}_{\mathrm{x}}$ & $\mathrm{TiN}_{\mathrm{x}} / \mathrm{TiN}_{\mathrm{x}}$ & $\mathrm{TiN}_{\mathrm{x}} / \mathrm{air}$ & \\
\hline$A$ & 103.9 & $\begin{array}{l}-1.70 \\
\end{array}$ & 105.4 & & 2.38 & & 10.5 & & 13.9 & 7.5 \\
\hline$B$ & 131.0 & -1.70 & 76.1 & & 2.63 & & 15.7 & & 14.3 & 11.9 \\
\hline$C$ & 245.1 & -0.31 & 210.3 & & 2.58 & & 37.8 & & 30.7 & 6.2 \\
\hline$D$ & 142.9 & -1.24 & 372.1 & & 2.44 & & 21.1 & & 32.9 & 7.0 \\
\hline$E$ & 92.2 & -1.90 & 338.1 & & 2.25 & & 5.0 & & 31.0 & 14.4 \\
\hline$F$ & 111.3 & -1.90 & 405.2 & & 2.57 & & 9.3 & & 29.9 & 2.8 \\
\hline$G$ & 151.7 & 0.82 & 150.8 & 103.6 & 3.33 & 2.13 & 10.9 & 12.3 & 12.5 & 7.9 \\
\hline$H$ & 154.5 & -1.90 & 344.6 & & 2.47 & & 22.3 & & 30.5 & 10.2 \\
\hline$I$ & 106.3 & -1.90 & 325.3 & & 2.51 & & 7.0 & & 24.9 & 6.1 \\
\hline$J$ & 175.9 & -1.90 & 31.4 & & 2.50 & & 6.1 & & 10.0 & 3.8 \\
\hline$K$ & 76.6 & -1.02 & 73.5 & 80.3 & 0.76 & 1.57 & 30 & 30 & 11.7 & 5.6 \\
\hline
\end{tabular}

a. The thickness and SLD of the native $\mathrm{SiO}_{\mathrm{x}}$ layer on top of Si substrate were fixed at $10 \AA$ and $3.5 \cdot 10^{-6} \AA^{-2}$, respectively. The SLD of Si substrate was fixed to the value of $2.07 \cdot 10^{-6} \AA^{-2}$. The $r m s$ roughness parameters for $\mathrm{Si} / \mathrm{SiO}_{\mathrm{x}}$ and $\mathrm{SiO}_{\mathrm{x}} / \mathrm{Ti}$ interfaces were $5 \AA$ and were kept constant during the refinement procedure. Fitting samples $G$ and $K$ required dividing the $\mathrm{TiN}_{\mathrm{x}}$ layer into two regions. 

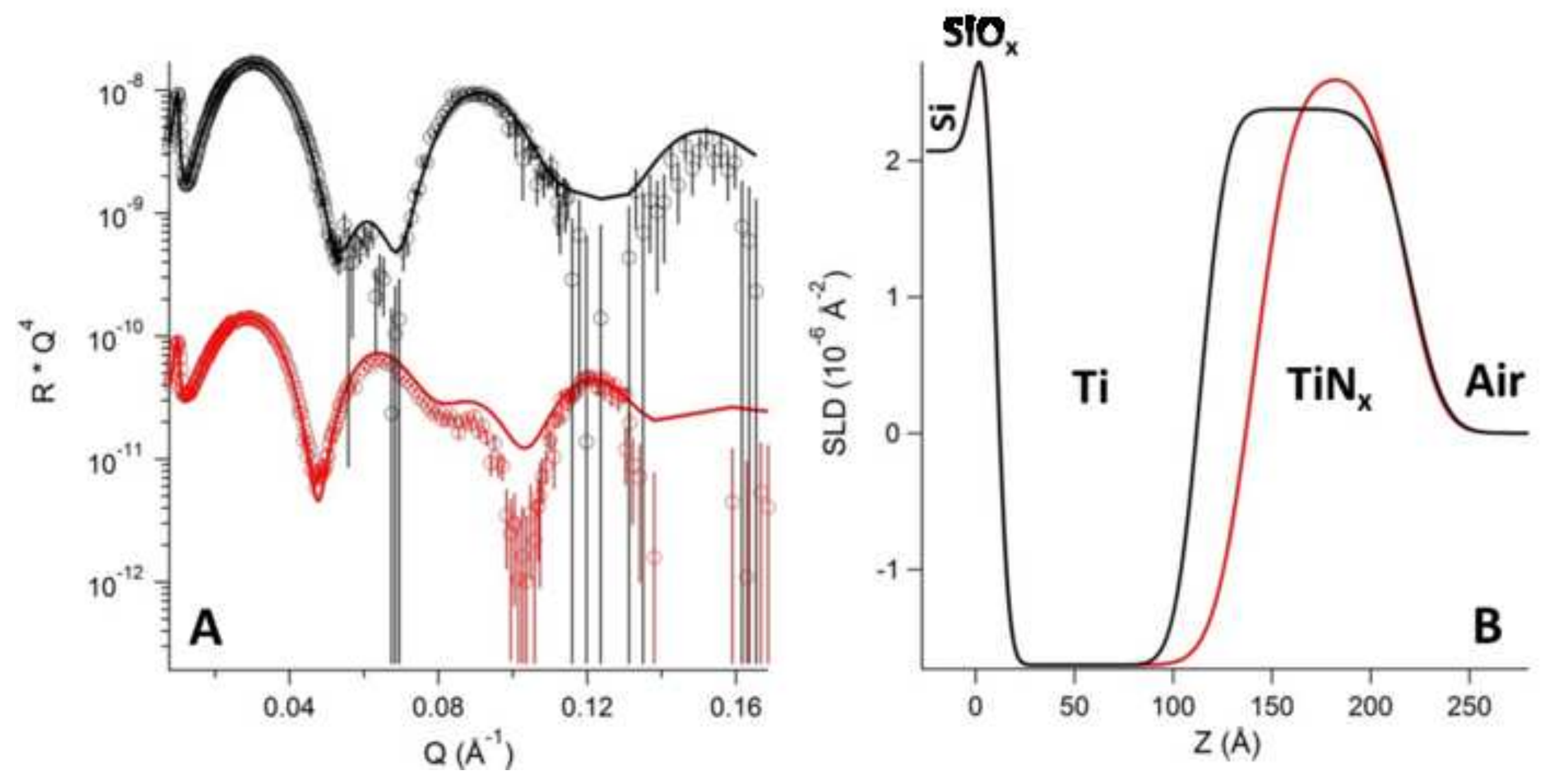

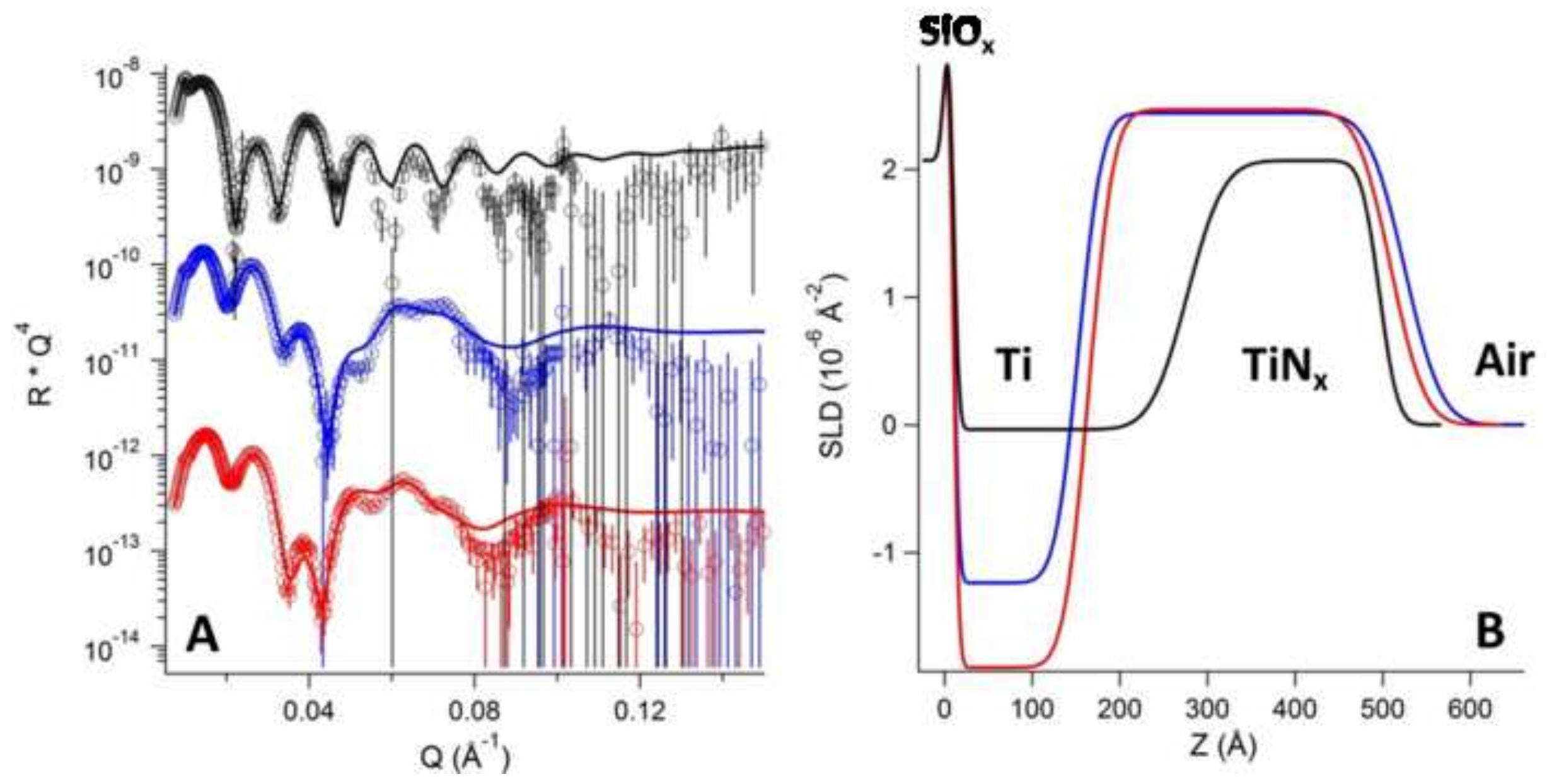

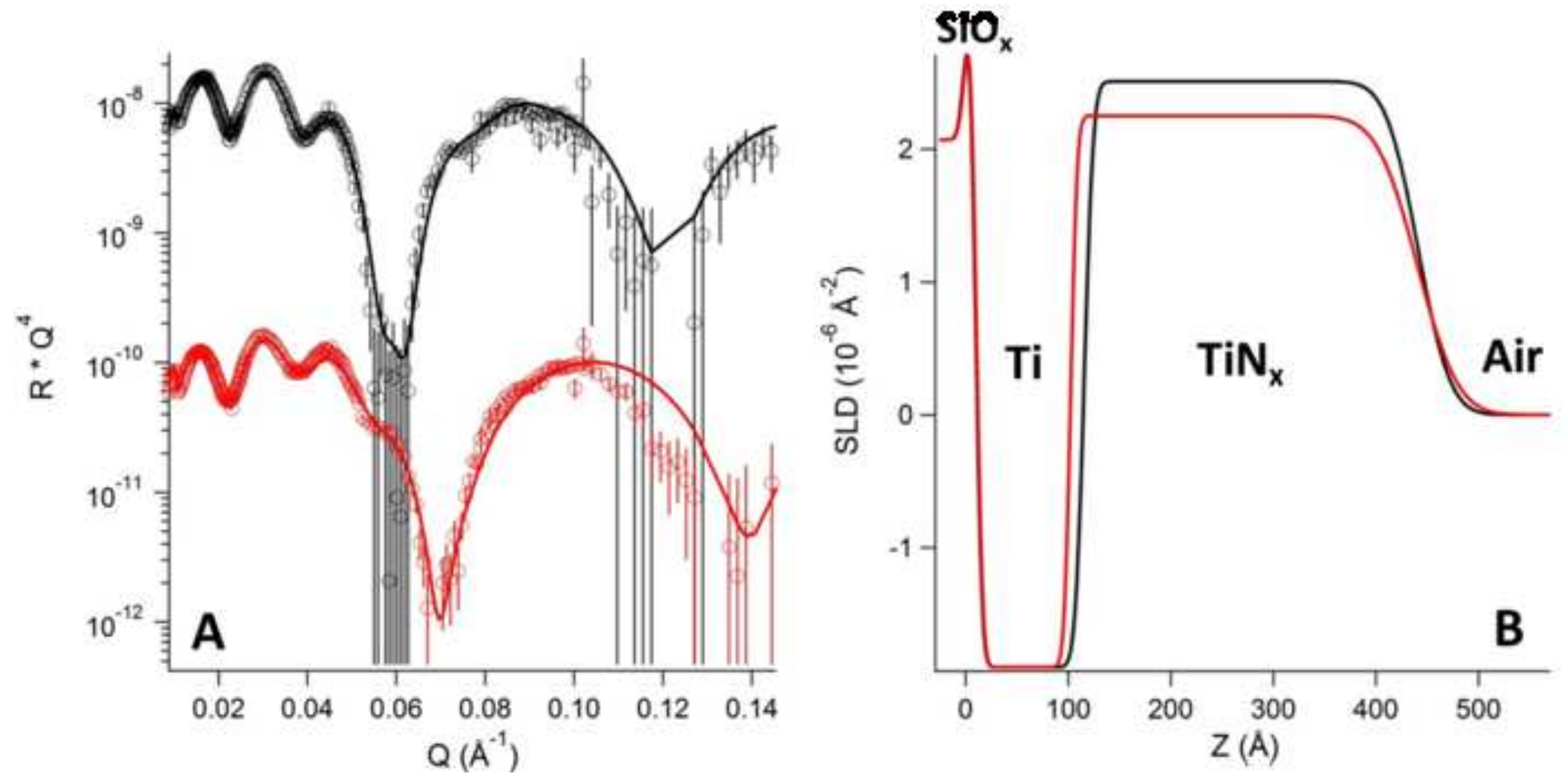

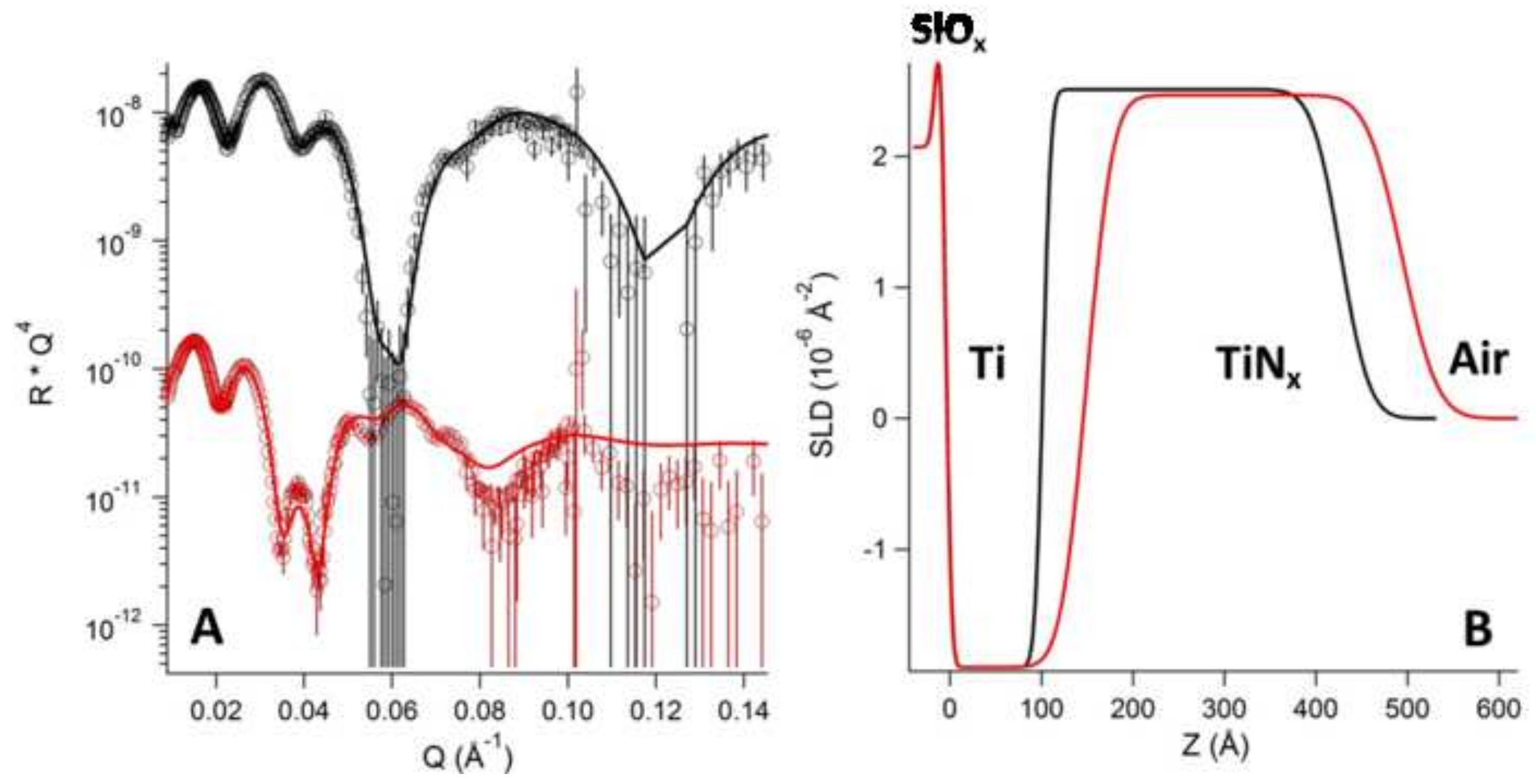

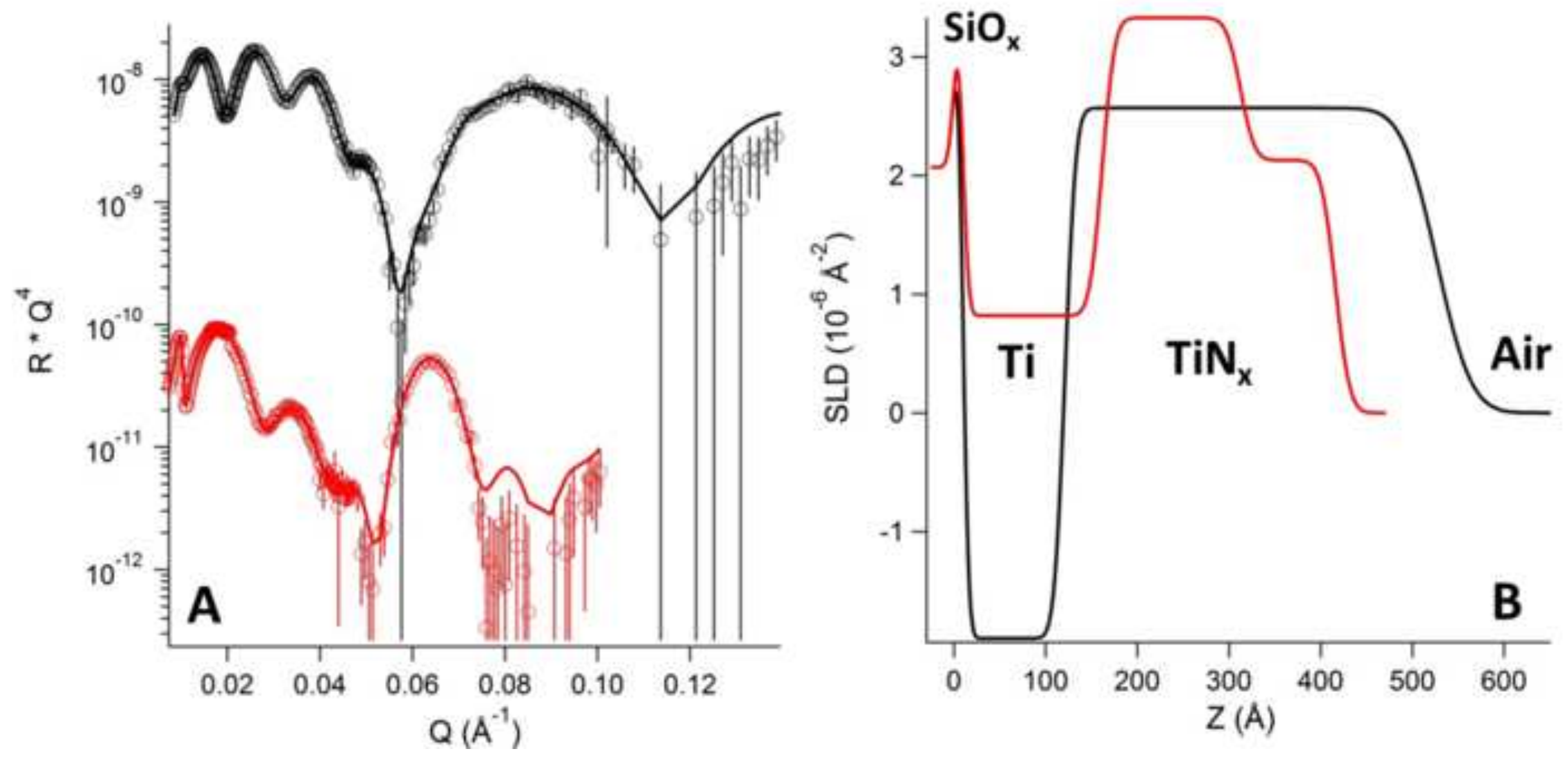

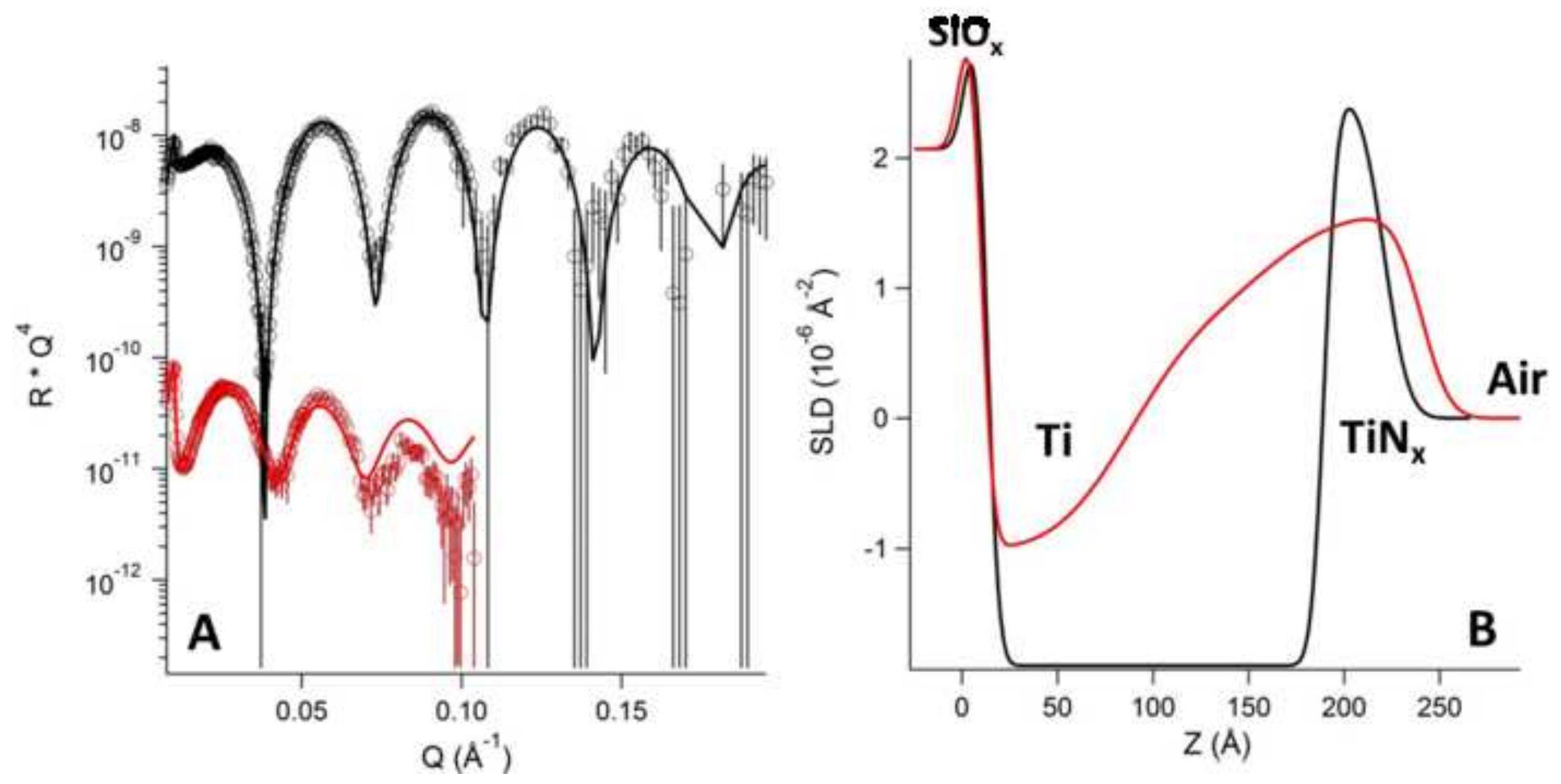

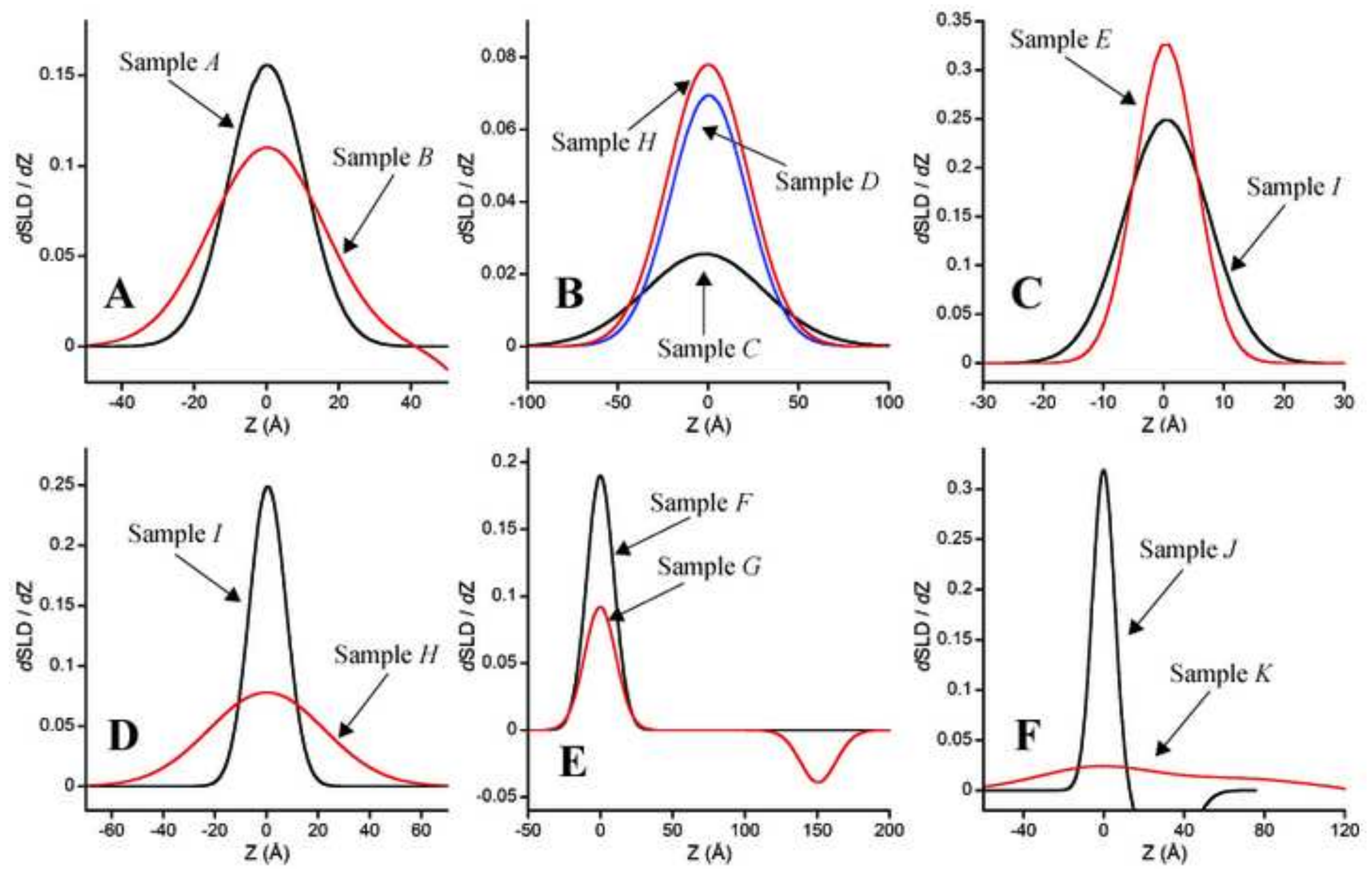